\title{
Gestación por sustitución internacional. Derecho a la vida privada y familiar en la doctrina y sentencia de 28 de abril 2017, Juzgado de Distrito Tabasco, México
}

Gestation by international substitution. right to private and family life in the doctrine and sentence of april 28, 2017, district court Tabasco, Mexico

Autores: Juan Antonio Flores Hernández, Gabriela Aguado Romero DOI: https://doi.org/10.25058/1794600X.997 


\section{GESTACIÓN POR SUSTITUCIÓN INTERNACIONAL. DERECHO A LA VIDA PRIVADA Y FAMILIAR EN LA DOCTRINA Y SENTENCIA DE 28 DE ABRIL 2017, JUZGADO DE DISTRITO TABASCO, MÉXICO*}

\author{
GESTATION BY INTERNATIONAL \\ SUBSTITUTION. RIGHT TO PRIVATE AND \\ FAMILY LIFE IN THE DOCTRINE AND \\ SENTENCE OF APRIL 28, 2017, DISTRICT \\ COURT TABASCO, MEXICO \\ GESTAC̄̃̃O POR SUBSTITUIÇÃO \\ INTERNACIONAL. DIŔEITO À VIDA PRIVAD́A E \\ FAMILIAR NA DOUTRINA E SENTENCA DE 28 \\ DE ABRIL DE 2017, TRIBUNAL DISTRITAL DE \\ TABASCO, MEXICO
}

\section{RESUMEN}

En abril de 2017, un tribunal federal, como órgano del sistema de control concentrado de constitucionalidad, ha emitido en Tabasco una sentencia sobre la determinación de la filiación de un menor derivada de un contrato de gestación por sustitución con un padre extranjero en un modelo familiar monoparental. En ese sentido, el discurso judicial materializa en forma expresa y tácita derechos fundamentales, que independientemente de la omisión de la indagación integral de la verdad biológica de quien aportó la carga gamética, implícitamente marcan pauta y herramienta al legislador y al ejecutivo local para el diseño de la política pública, en relación a la inmediatez del registro de nacimiento de un niño sin necesidad

\footnotetext{
* El presente artículo se enmarca en el Proyecto de Investigación Científica "La gestación por sustitución en el discurso de los sistemas interamericano y europeo de derechos humanos" y en conjunto es el resultado parcial de una estancia de investigación en el Departamento de Derecho Internacional Privado de la Universidad de Salamanca, España; con el apoyo del Capítulo Guanajuato de la Academia Nacional de Bioética, A.C., el Proyecto Inocencia con residencia en la ciudad de Guanajuato, México, perteneciente a la red InnocenceProyect con sede en California Wester School of Law, U.S.A.y, la Fundación para la Defensa y Promoción de los Derechos Humanos sita en Costa Rica.
}

a Abogado egresado de la Universidad de Guanajuato, Maestro en Derecho Civil por la Universidad de la Salle, León Guanajuato, Candidato a Doctor en Ciencias Jurídicas del Programa Nacional de Posgrados de Calidad, Facultad de Derecho de la Universidad Autónoma de Querétaro, México. ORCID https://orcid.org/0000-0003-2306-3672

b Abogada egresada de la Facultad de Derecho de la Universidad Autónoma de Querétaro, Especialista en derecho notarial y Especialista en derecho Fiscal, con estudios de Maestría y Doctorado en derecho por la Univerisdad Autónoma de Querétaro, México, docente investigador de tiempo completo, Miembro del Sistema Nacional de Investigadores SNI, Miembro del Cuerpo Académico consolidado Derechos Humanos y Globalización CAC128-FDEUAQ, ORCID https://orcid.org/0000-0003-3733-6459
Juan Antonio Flores Hernández ${ }^{\mathrm{a}}$ lic.flores8@gmail.com Gabriela Aguado Romero aguadogabriela@hotmail.com Fecha de recepción: 05 de julio de 2018 Fecha de revisión: 08 de agosto de 2018 Fecha de aceptación: 05 de octubre de 2018
Para citar este artículo: Flores, J. (2019). Gestación por sustitución internacional. Derecho a la vida privada y familiar en la doctrina y sentencia de 28 de abril 2017, juzgado de distrito Tabasco, México. Revista Misión Jurídica, 12, (16), $79-96$. 
de agotar instancias judiciales previas sobre la preponderancia de la parentalidad biológica, y la implícita omisión de las presunciones del parto.

\section{PALABRAS CLAVE}

Gestación por sustitución internacional; filiación; derechos fundamentales; tutela judicial.

\section{RESUMO}

Em abril de 2017, um tribunal federal, como órgão do sistema de controle concentrado de constitucionalidade, emitiu em Tabasco uma sentença sobre a determinação da filiação de um filho derivada de um contrato de gestação por substituição com um pai estrangeiro em um modelo de família monoparental. Nesse sentido, o discurso judicial materializa expressamente e tacitamente os direitos fundamentais, que independentemente da omissão da investigação integral da verdade biológica de quem trouxe a carga genética, eles implicitamente estabelecem a diretriz e a ferramenta para o legislador e o executivo local para o desenho de política pública em relação ao imediatismo do registro de nascimento de uma criança sem a necessidade de esgotar as instâncias judiciais anteriores sobre a preponderância da paternidade biológica e a omissão implícita das presunções do parto.

\section{PALAVRAS-CHAVE}

Gravidez por substituição internacional; filiação; direitos fundamentais; proteção judicial.

\section{PALABRAS CLAVE}

Gestación por sustitución internacional; filiación; derechos fundamentales; tutela judicial.

\section{ABSTRACT}

In April 2017, a federal court as a part of the system of constitutional condensed control has released in Tabasco a sentence on the determination of filiation of a minor derived of a gestation by substitution agreement with a foreigner parent in a single-parent family. In this respect, the judicial discourse embodies in an explicit and tacit manner fundamental rights, that regardless the omission on the integral enquiry of the biological truth of whom contributed with the gametic load implicitly mark a difference and a tool for the legislator and for the local officials to design a public policy in connection with the immediacy of giving a birth certificate of a child without the need of exhausting previous judicial instances on preponderance of biological parenthood and the implied omission of the presumptions of delivery.

\section{KEY WORDS}

Gestation by international substitution, filiation, fundamental rights, judicial protection

\section{INTRODUCCIÓN}

Existe una gran controversia doctrinal en relación con la gestación por sustitución. En el ámbito interno para delimitar el alcance, convivencia, efecto mitigado de los derechos individuales de carácter fundamental con el orden público y el interés social. Asimismo, en materia del derecho internacional privado, en la tendencia en que las personas se desplazan al extranjero (Flores, 2014: 71-89), a los países donde está permitida o es posible por no estar técnicamente prohibida.

El margen de apreciación nacional, como criterio hermenéutico de deferencia frente a circunstancias donde no existe consenso interestatal, que ha de tener cada país y en el caso de México cada entidad federativa permite definir el propio orden público e interés social que ha de prevalecer respecto de la gestación por sustitución. Una vez que han nacido los niños los problemas que se suscitan con su identidad son en el ámbito interno el establecimiento de su filiación correspondiente y, en el externo el reconocimiento de esa filiación ya establecida al desplazarse al Estado donde se busca que resida permanentemente como fue el caso en España con la resolución del Tribunal Supremo de 2 de febrero de 2015 (Durán, 2012: 268-269), en Francia con los asuntos Mennesson y Labassee o en Italia con el caso Paradiso y Campanelli. Es el poder judicial quien a posteriori ha de contextualizar y ponderar los derechos y principios en colisión con un efecto mitigado o justificado del orden público y en su caso, definiendo la molestia que debe tolerar la sensibilidad social, objetivándose diversos y divergentes discursos jurisprudenciales.

En ese panorama existen pronunciamientos jurisprudenciales ajustados en exclusividad a la litis trabada a través de las pretensiones, 
resistencia u omisiones probatorias de las partes y sujetos procesales. Que en ese contexto pueden ofrecer un criterio orientador o develar un límite mínimo, que el juzgador puede utilizar para extender la demarcación material o resolver un enfrentamiento de derechos fundamentales no absolutos por ser interdependientes, en base a la tópica de mayor protección o el menor perjuicio. Son los Sistemas de Protección Europeo e Interamericano de Derechos Humanos los que pueden dialogar en su caso con los discursos judiciales que se han de construir en cada caso en particular ante la inexistencia o convivencia de un estatuto jurídico homogéneo.

El propósito de este artículo es comentar la sentencia de 28 de abril de 2017 emitida por un Juzgado de Distrito en Tabasco, analizando el problema del asentamiento del registro de la filiación derivada de un acuerdo de gestación por sustitución internacional (previo procedimiento de adopción) en relación a la menor nacida y su padre de intención, la incidencia del parámetro genético y la social estabilidad familiar. Demostrando que la tramitación del incidente de suspensión en el juicio de amparo y la sentencia de fondo: (i). Maximizan el perímetro material en el acceso a la identidad del menor que de la interpretación del derecho a la vida privada y familiar han definido los discursos de los Sistemas de Protección Europeo e Interamericano de Derechos Humanos y; (ii). Hacer notar que la resolución expresa, tácita y de manera programática marca pauta al legislador y al ejecutivo local para el diseño de la política pública sobre la gestación por sustitución en relación: a) al registro inmediato de un menor por quien acredite la parentalidad genética con independencia de las circunstancias del nacimiento como garantía de igualdad y acceso efectivo a la identidad del menor y la autodeterminación de los padres de intención; b) el reconocimiento y protección de la vida privada y la preservación de los lazos de facto de la vida familiar del menor y los padres de intención y; c) la ponderación del principio del interés superior del niño con la carga ideológica y efecto atenuado del orden público. Así, se evidenciará la necesidad al menos de clarificar parámetros administrativos en materia registral en las entidades federativas o en las embajadas y consulados mexicanos tanto para extranjeros como para mexicanos.
En la especie, el señor Aaron Ray Cyr, de nacionalidad estadounidense, por su propio derecho y en representación de su hija menor Rachel Mary Cyr, recién nacida mediante gestación por sustitución con la aportación de su material genético, promovió juicio de amparo en contra de diversos actos de autoridad, solicitando la protección de la justicia federal, esencialmente contra: a) La inconstitucionalidad de los artículos que reformaban la legislación civil del Estado de Tabasco en lo relativo a la gestación por sustitución; b) La aplicación en perjuicio de la reforma legislativa por ser retroactiva; c) El acuerdo SG/DGRCT/153/2016 emitido por la Dirección del Registro Civil del Estado de Tabasco, el cual declaró improcedente la solicitud de registro de una menor por su padre de intención; d) El desconocimiento de esa paternidad y; e) Los posibles actos de separación del menor.

\section{METODOLOGÍA}

Mediante el Análisis Crítico del Discurso se busca descifrar semánticamente el núcleo duro y discurso político del derecho a la salud reproductiva mediante gestación por sustitución, colocando al centro de la discusión aquellos elementos que permanecen expresos u ocultos en el discurso jurídico.

\section{RESULTADOS}

La figura, principio, tópica, técnica o doctrina del margen de apreciación nacional, es un modelo de aproximación compartido por la Corte Europea e Interamericana de Derechos Humanos, el cual demarca la concepción en que los Estados partes limitan los derechos reconocidos en las respectivas convenciones.

La Corte Europea de Derechos Humanos, ha permitido la limitación estatal de los derechos, reconociendo que el margen de apreciación (discrecionalidad) es consustancial al principio democrático y a la soberanía nacional de los estados partes, puesto que la valoración del interés colectivo superior en cada sociedad resulta una tarea política sensible y menos jurídica; empero dicha individualidad descansa en una presunción de que la decisión y su consecuente regulación opera de manera transparente y permite la participación efectiva en una democracia consolidada. 
En el ámbito interamericano, se habla de la necesidad de un control más garantista, frente a una crónica sistemática de violación de derechos humanos, donde la aplicación del derecho es insuficiente y el margen de apreciación es marginado y no frecuente.

Un punto de encuentro entre ambos sistemas es el parámetro de proporcionalidad racional, para Europa la verificación para no rebasar el margen de apreciación en las limitaciones estatales y, para América la compatibilidad de las limitaciones con la Convención.

Europa ha sido permisiva en el margen de los países para determinar lo que es de utilidad pública en materia económica y social, mientas que América vincula los derechos sociales con los civiles y políticos

La autoridad pública que ejercen los tribunales internacionales constituye una gobernanza global que refracta en la construcción normativa (más allá del Estado, antes de él o incluso contra la ley de aquél) y en la redistribución del poder y de los recursos sobre órganos colectivos con legitimación democrática que ordinariamente definen presupuesto y prioridad de aplicación. Erigiéndose en un constitucionalismo supraestatal o constitucionalismo sin Estado. Lo que entraña la consideración de la relación de pluralidad jurídica entre el Derecho Constitucional y el Internacional Público, que sirve de guía de interacción de la función de los jueces nacionales en un Estado constitucional de cooperación y solidaridad, más allá de la voluntad estatal frente a la asunción de obligaciones internacionales.

\section{Tabasco, la noticia de la denegación de actas de nacimiento a padres de intención extranjeros y el esbozo del contexto internacional}

Entre finales de febrero y principios de marzo de 2017 se publicitó en la prensa mexicana la noticia de que, en el Estado de Tabasco, el Registro Civil había denegado la expedición de actas de nacimiento a por lo menos 11 niños nacidos por gestación por sustitución ante la solicitud de "padres de intención" extranjeros: españoles, israelíes, italianos, griegos, franceses y estadounidenses. Situación en la que se encuentran por nacer al menos 100 niños más (Hernández, 2017).
En la Ciudad de México, en una entrevista televisiva en cadena nacional, el coordinador jurídico de la dirección general del Registro Civil del Estado de Tabasco (Televisa, 2017), realizó afirmaciones sobre la motivación de la negativa de expedir las actas de nacimiento aludiéndose: al respeto al orden jurídico; el fraude a la Ley o fórum shopping (Reinoso, 2009); el interés superior del menor y su derecho a la identidad al no ver reconocida la filiación en el extranjero; evitar la mercantilización, el tráfico de menores, las nuevas formas de esclavitud para evadir las leyes de seguridad social de otros países y la salud pública ${ }^{1}$.

En relación con los juicios de amparo instados por distintos solicitantes (quejosos) contra la denegación de las certificaciones de nacimiento, el coordinador jurídico aludió la contradicción de las medidas provisionales que se consideraron en relación con los menores: por un lado se estableció que la guardia y custodia debía permanecer bajo los "padres posibles" mientras que por otra parte, se estimó que no procedía que estos se mantuvieran en el cuidado de los niños, mero al no especificarse por los juzgadores que los menores debían quedar bajo la tutela del Estado ${ }^{2}$, el Gobierno decidió no separar a los menores. Destacando la singularidad de un juzgado de distrito que ordenó expedir un acta provisional, lo que se consideró inadecuado al invadir el juzgador la esfera del legislador en la medida de la inexistencia de esa figura en la ley.

El problema de inmediatez del reconocimiento de nacionalidad o de los documentos para el desplazamiento del menor al país de residencia de los padres de intención o comitentes, que se plantea de fondo es tanto para hijos de mexicanos o extranjeros que nacen en territorio nacional para el establecimiento de la debida filiación correspondiente, en los diversos estados de la

1. Se adujo a la existencia de "mafia" detrás de la gestación por sustitución, citándose el caso de un extranjero con residencia en Nueva Zelanda que había celebrado acuerdos con cuatro mujeres, tres en Cancún (donde no hay regulación) y una en Tabasco, el cual mediante partos gemelares, había engendrado a ocho menores; contagio y abandono a mujeres y niños con el síndrome de inmunodeficiencia humana (SIDA); situación de parejas de setenta años o más - a las que se les ha entregado acta de nacimiento- que han verbalizado que la idea de incorporar al núcleo familiar a menores a tan avanzada edad es para que cuiden de ellos (asear, dar medicamentos).

2.La Corte Europea de Derechos Humanos, en el caso Paradiso y Campanelli, sostuvo legítima la intervención de Italia que separó al menor de los padres de intención al declararlo en abandono por quien sufrió el parto, dándolo en adopción. 
república que regulan o no prohíben la gestación por sustitución; como para hijos de mexicanos que nacen fuera del territorio nacional y acuden a las representaciones consulares a tramitar el correspondiente reconocimiento de la filiación ya establecida en el extranjero a favor de los padres de intención o comitentes. La diversidad del panorama va depender de los principios de iussanguinis, iussoli, mater semper certaest o paterisestquemnuptiaedemostrant.

En el supuesto de los hijos de mexicanos que nacen en el extranjero o hijos de extranjeros que nacen en el territorio nacional mediante gestación por sustitución ${ }^{3}$, su inscripción y filiación correspondiente quedará al arbitrio, sospecha o incomprensión de la persona ante quien se presente el inicio del trámite, dependiendo de la documentación que se presente (sentencia judicial extranjera que declare la filiación intencional o certificado de nacimiento a favor de la gestante). El problema de apreciación de la autoridad no es menor, si, además, se agrega el modelo familiar en el que se procura al menor. La asociación civil Litigio Estratégico en Derechos Sexuales y Reproductivos (Ledeser, 2017), publicita dentro de sus logros en 2014 haber obtenido el primer pasaporte expedido en México por la secretaría de relaciones exteriores en favor de una familia lesbomaternal por reconocimiento de hijos. En 2015 el primer reconocimiento de hijos para una familia homoparental por gestación subrogada en México, pasaportes para hijos de familia lesbomaternal previamente negados por la secretaría de relaciones exteriores y haber organizado como actividad de capacitación el panel Gestación pos Sustitución Aspectos Internos y Transfronterizos en el aula magna de la División de Estudios Jurídicos del Centro de Investigación y Docencia Económicas en la Ciudad de México. La Comisión Estatal de Derechos Humanos en Chihuahua informa que en 2017 emitió la recomendación 14/2017 a la Dirección del Registro Civil de ese Estado. Ante la negativa a registrar con el apellido de sus madres a sus dos hijos recién nacidos mediante inseminación artificial en la Ciudad de Chihuahua, quienes no pudieron ser inscritos al sector salud y a los servicios de seguridad social, se estimó acreditada

3.Conforme al artículo 30, inciso A, fracciones I, II y III, de la Constitución Política de los Estados Unidos Mexicanos, son mexicanos por nacimiento los que nazcan en territorio nacional cual fuera la nacionalidad de los padres y los que nazcan en el extranjero siendo hijos de padres mexicanos por nacimiento o naturalización. la violación al derecho de legalidad y seguridad jurídica a un matrimonio de mujeres, así como al derecho a la identidad y a la igualdad de los recién nacidos como hijos de familias lesbomaternales.

En el contexto internacional, en España, el 6 de febrero de 2014, el Tribunal Supremo de España se pronunció, por primera vez, en un caso de gestación por sustitución internacional que involucra los derechos de dos menores y de un matrimonio conformado por dos personas de sexo masculino. La sentencia confirmó lo decidido en las instancias previas (cancelar la inscripción de nacimiento) $y$, consecuentemente, dejó a estos menores sin la nacionalidad española y sin los beneficios que devienen de su titularidad. Lo resuelto en esta sentencia fue luego confirmado por el Pleno de la Sala de lo Civil del Tribunal Supremo en un auto del 2 de febrero 2015, recurso núm. 245/2012 (Flores, 2014: 71-89). El Pleno recalcó que la sentencia protege el interés de los menores pues permite la fijación de las relaciones paterno-filiales mediante la determinación de la filiación biológica paterna mediante impugnación judicial y la formalización de las relaciones familiares de "facto" mediante la adopción o el acogimiento, protegiendo en todo momento la unidad familiar en que puedan estar integrados los menores (Durán, 2012: 268-269), instando al Ministerio Fiscal para que adoptara las medidas pertinentes, en el sentido indicado, para la protección de las niñas y niños.

En Francia, existen como referentes las sentencias emitidas por la Corte Europea de Derechos Humanos sobre los asuntos: Mennesson y Labassee de junio de 2014, Foulon y Bouvet de julio de 2016. En los cuatro supuestos uno de los padres de intención aportó su material genético; en los dos primeros se pedía la trascripción de la sentencia estadounidense que establecía la filiación del menor en relación con los comitentes, anulándose la inicial inscripción para posteriormente impedírseles jurisprudencialmente, la vía del reconocimiento y la adopción. La diferencia con los últimos dos, estriba en que se solicitada el establecimiento de la filiación del menor con los padres de intención por la vía de posesión de estado de hijo. Francia negó, anuló e impidió por todo medio administrativo y judicial el reconocimiento de la filiación derivada del acuerdo de gestación por sustitución establecida en el extranjero por violar el orden público internacional francés. La 
Corte Europea de Derechos Humanos estimó que no se había violado el respeto a la vida familiar de los solicitantes en tanto que de hecho habían podido vivir como familia de facto, empero sí consideró violado el derecho a la vida privada de los menores por habérseles impedido en forma absoluta el establecimiento de la filiación con los padres de intención, máxime que por lo menos uno de ellos era el biológico.

En Alemania, en la sentencia de 10 de diciembre de 2014, el Tribunal Federal de Justicia (Bundesgerichtshof, 2014) anuló una decisión de un tribunal inferior, estableciendo que la sentencia del Estado de California que reconoce a una pareja homosexual como los padres legales de un niño nacido por gestación por sustitución en los Estados Unidos de Norteamérica debe ser reconocida en Alemania. Cabe destacar que esta decisión representa una desviación del anterior caso del Tribunal Federal (Lamm, 2016: 149-170), y se basó en las decisiones de los asuntos Mennesson y Labassee de la Corte Europea de Derechos Humanos, considerando que no resultaba en el caso concreto contraria al orden público internacional alemán, destacando la importancia de una interpretación restrictiva del orden público respetuosa con el interés superior del menor y la conveniencia de evitar situaciones jurídicas claudicantes. En el citado caso fue determinante la aportación de material genético por parte de uno de los miembros de la pareja de varones (Durán, 2016), que la gestante no aportó su carga genética y que no existió conflicto entre la gestante y los padres de intención.

En relación a la motivación del tribunal alemán, existía un precedente en los Estados Unidos, donde existió el arrepentimiento de la gestante para entregar al menor, esta aportó el componente genético y el varón comitente aportó su carga genética. El asunto resuelto por la Suprema Corte de New Jersey, case In re Baby M, 537 A.2d 1227, 109 N.J. 396 (N.J. 02/03/1988) mejor conocido como el caso de "Baby M" (Silva, 2001). En la primera instancia (el juez Sorkow), declaró válido y ejecutable el contrato de gestación por sustitución, con la base de que era lo mejor para la menor se concedió la custodia exclusiva al padre comitente el señor Stern, separando a la gestante Mary Beth Whitehead y, patrocinó una orden de adopción a la señora Stern. El tribunal de alzada, la Corte Suprema de New Jersey (el 3 de febrero de 1988) considerando violadas las leyes del Estado, confirma la concesión de la custodia al padre genético, revoca la declaración de la pérdida de los derechos maternos de la gestante, requiriendo al inferior a efecto de que determinara las modalidades de la convivencia entre esta y la menor (Richards, 2015).

En Italia, la Gran Sala de la Corte Europea de Derechos Humanos en enero de 2017, hizo pública la sentencia del asunto Paradiso y Campanelli4; el tribunal estimó los ocho meses de convivencia con el menor como breves, aunado a la ausencia de vinculo genético y la inseguridad jurídica creada al traer los comitentes a Italia trasgrediendo las leyes de adopción y reproducción asistida del orden público internacional italiano, concluyendo así que no existió vida familiar de factoy no existió violación a la vida privada y familiar. Se realza que la distinción de los casos franceses era la no correspondencia genética de los comitentes; el objetivo no era la inscripción registral expedida en Rusia ni el reconocimiento de la filiación resultante, sino la declaración de desamparo del menor por parte de las autoridades italianas, siendo que el menor no era parte en el proceso debido a la separación de los comitentes y el acogimiento de la familia de adopción (Farnós, 2017).

En noviembre de 2015 en Colombia, la Corte Constitucional falló sobre una acción de tutela interpuesta por una pareja de hombres que en su momento no pudo registrar a sus dos hijos, nacidos en California, dando un plazo para que se adecúe el formato de los registros de nacimiento y que estos admitan a los hijos de parejas del mismo sexo (Lamm, 2016: 149-170).

4.Un matrimonio heterosexual recurre a la gestación por sustitución en Rusia, el menor fue inscrito en ese país como hijo del matrimonio. El consulado en Moscú expidió la documentación que permitió al niño viajar a Italia. La pareja intentó inscribir el nacimiento del infante en Collerorto pero la solicitud fue denegada. Posteriormente, al informar el Consulado que el expediente sobre el nacimiento contenía información falsa al no haberse informado el acuerdo de gestación, proceso ilegal en el Estado Italiano, se acusó a la pareja de alteración del estado civil $y$ de incumplimiento de la legislación italiana internacional sobre adopción. El tribunal de Campobasso, conforme a la legislación italiana, declaró abandonado al menor al considerarse a la gestante como madre, considerando la inexistencia de filiación biológica (la prueba de paternidad había sido negativa, se había utilizado en vez del semen del señor Campanelli el de un donante) y el fraude a la ley, separó al menor, prohibió contacto y posibilidad de que los comitentes intervinieran en el proceso de adopción. Acogido el menor en una familia adoptiva se estableció en el correspondiente certificado que los padres eran desconocidos. 
En Argentina de 2012 a 2016, se encuentran diversos casos de niños nacidos por gestación sustituta internacional: el de un matrimonio homosexual cuyos gemelos nacen en Rusia; una pareja no casada que celebró un acuerdo en la India utilizando un óvulo donado y esperma de uno de ellos; la niña de una madre argentina y un padre español, ambos residentes españoles, que nació en la India y quien se encontró durante semanas en un limbo jurídico varada en ese país ante la negativa Española para otorgar los documentos de viaje (Lamm, 2016: 149-170).

En México, el caso de una pareja casada que recurre a la gestación por sustitución en la India, naciendo mellizos (Lamm, 2016: 149-170).

\section{Identidad del menor y no agotamiento de instancias previas}

En el caso de Tabasco, en relación con la negativa del registro del nacimiento de la menor fue ventilado previamente ante el fuero común (o ámbito local) correspondiente al Poder Judicial del Estado de Tabasco, ámbito en donde fue desechada la presentación de la demanda en el cuadernillo de desechamiento número 10/2017 del índice del Juzgado Tercero Familiar de Primera Instancia del Distrito Judicial del Centro, desconociéndose las causas sustantivas o procesales por las que no se dio entrada a la demanda y se dio trámite al correspondiente juicio, empero dicha documental fue glosada al juicio de amparo (Consejo de la Judicatura Federal, 2017).

En forma independiente y posterior, al tratarse de un acuerdo en virtud del cual la Dirección del Registro Civil del Estado de Tabasco negaba la expedición del acta de nacimiento de la menor, esto es, un acto administrativo emitido fuera de procedimiento, se promovió juicio de amparo indirecto del que conoce un juez de distrito, como órgano federal del sistema de control concentrado de constitucionalidad y convencionalidad.

La Dirección General del Registro Civil del Estado de Tabasco y su Coordinación Jurídica, rindieron sus informes justificados en el sentido de que no declararon improcedente el registro de la mencionada infante, sino que solo se concretaron a manifestar las razones por las que resultaban incompetentes para asentar a la menor, nacida mediante el procedimiento de "gestación materna sustituta", puesto que atendiendo a que la transferencia embrionaria tuvo lugar el siete de abril de dos mil dieciséis, durante la vigencia de los artículos 380 bis, 380 bis 1,380 bis 2,380 bis 3,380 bis 4,380 bis 5,380 bis 6 y 380 bis 7 del Código Civil del Estado de Tabasco, quien tenía legalmente esa potestad era el juez competente, a través de un procedimiento no contencioso de adopción plena, lo que no implicaba una orden para separar al peticionario de amparo de su menor hija, ni tampoco un desconocimiento de su paternidad y mucho menos la negativa de expedir el acta de nacimiento de la infante.

En lo que aquí interesa, los artículos en comento disponen los requisitos que deben cumplir las partes contratantes, entre otros: ser una pareja en matrimonio o concubinato (padre y madre); la "madre contratante" padecer imposibilidad física o contraindicación médica para llevar acabo la gestación en su útero; ser ciudadanos mexicanos, el asentamiento del recién nacido deberá realizarse mediante la figura de la adopción plena -con independencia de la aportación genética de los padres de intención-.

Por su parte, otras de las autoridades responsables, delegada de la secretaría de relaciones exteriores y titular del Poder Ejecutivo (gobernador constitucional del Estado de Tabasco), adujeron como causa de improcedencia del juicio de amparo: la falta de interés legítimo de los solicitantes en virtud de que no demostraron que la expedición y promulgación del decreto por el que se adiciona los artículos tachados de inconstitucionales le cause una afectación a su interés jurídico. Planteamiento a lo que el juez federal, evocando a un bloque de constitucionalidad, concluye en la sentencia textualmente:

(...) sí afectaba su derecho a la identidad y a ser registrada de manera inmediata a su nacimiento, debido a que los obligaba a agotar una instancia judicial previamente al registro de la infante, lo que no está previsto en la legislación constitucional y secundaria nacional, que regula lo relativo a los derechos de las niñas, niños y adolescentes, ni en los tratados internacionales de los que el Estado Mexicano es parte; en consecuencia el acuerdo reclamado si lesiona el interés jurídico de los quejosos.

El desarrollo jurisprudencial de la Corte Interamericana y Europea de Derechos Humanos 
ha referido en relación al ámbito de la vida privada. La existencia de un atributo personal para organizar la vida individual y social (Juan Chaparro y Lapo Fredy. Vs. Ecuador, 2007, párr. 52). Un espacio de respeto de la elección a las propias opciones y convicciones que le dan sentido a la existencia (Atala Riffo y Niñas Vs. Chile, 2012, párr. 136) para definir las propias relaciones personales, esto es, establecer y desarrollar relaciones con otros seres humanos y con el mundo exterior como elemento constitutivo de la identidad física y social; cuya protección efectiva permite ejercer la directriz personal sobre el futuro curso de los eventos relevantes para la calidad de vida de la persona (R.R. Vs. Polonia, 2011, párr. 197), en tanto que abarca la forma en que el individuo se ve asimismo y como decide proyectarse hacia los demás (Rosendo Cantú y otra Vs. México, 2010, párr. 119; Atala Riffo y Niñas Vs. Chile, 2012, párr. 162; Dudgeon Vs. Reino Unido, 1981, párr. 41; X y Y Vs. Países Bajos, 1985, párr. 22; Niemietz Vs. Alemania, 1992, párr. 29; Peck Vs. Reino Unido, 2003, párr. 57; Pretty Vs. Reino Unido, 2002, párr. 61).

En segundo lugar, se ha estimado la protección del espectro de la vida privada, el principio del interés superior de la niñez y el deber de garantizar su supervivencia y desarrollo, están íntimamente relacionados con la protección de la vida familiar en la existencia de un menor y en la sociedad, con la adquisición y preservación de la identidad del menor: la nacionalidad y la protección de la organización y desarrollo de la familia (relaciones familiares), lo que impera a la prohibición de restricciones desproporcionadas e innecesarias de iure o de facto para que el menor establezca su filiación correspondiente con tendencia biológica en la medida de lo posible, ser cuidado por sus padres, ponderándose que el mejor interés del menor puede estar en la preservación de una filiación de estabilidad de relaciones familiares sin corresponder a la verdad biológica sabida o por indagar. Asimismo, en la condición de que una madre o unas madres o un padre o unos padres puedan registrar al menor sin distinción (igualdad) en virtud de las circunstancias de su nacimiento.

El esbozo que antecede, versa sobre una dialógica más que liberal, comunitaria.

En sentido genérico se puede afirmar que la trascrita conclusión del juzgador es congruente con el desarrollo jurisprudencial de la Corte Interamericana y Europea de Derechos Humanos.

Por su parte, en el ámbito de los sistemas de protección de derechos humanos, la Corte Interamericana ha sostenido que a diferencia del Convenio Europeo de Derechos Humanos, en el cual solo se protege el derecho de la vida familiar bajo el artículo 8, la Convención Americana cuenta con dos artículos que protegen la vida familiar de manera complementaria (Atala Riffo y Niñas Vs Chile, 2012, párr. 175), consecuentemente, se ha indicado que la protección de la familia es un derecho tan elemental que no se puede derogar aunque las circunstancias sean extremas, por lo que existe obligación de favorecer de la manera más amplia el desarrollo y fortaleza del núcleo familiar (Gelman Vs. Uruguay, 2011, párr. 125; Atala Riffo y Niñas Vs. Chile, 2012, párr. 169; CIDH, Opinión Consultiva OC-17/02, párr. 66).

De relevancia emblemática, los asuntos Mennesson y Labassee, ambos contra Francia, en los que por primera vez la Corte Europa de Derechos Humanos (CEDH) se pronunció sobre el alcance y trascendencia del interés superior del menor en el establecimiento de la filiación de la gestación por sustitución, haciendo posible desde el nacimiento del niño que su filiación quede acreditada, sin que ello pueda verse afectado por el diferente tratamiento normativo que sobre ese acto reproductivo pueda haber en el país en que residen los padres intencionales y donde residirá el propio menor. Se consideró que denegar la inscripción de los menores en el Registro Civil francés vulnera el derecho que tienen los niños al respeto a su vida privada, que puede verse afectada por la indeterminación de su identidad filial. Indeterminación que, además, lleva a privarlos de la nacionalidad francesa y de todos los derechos que se derivan de la misma, máxime como cuando en la especie, los niños eran hijos biológicos de los padres. En su momento, la doctrina europea (Durán, 2014: 280-282) cuestionaba al Tribunal de Estrasburgo en el sentido de que era tácito que la condición que orientó la sentencia era la paternidad biológica de los padres de intención, empero, como es ahora la del caso mexicano ¿Que hubiera sucedido si no se hubiera aportado el material genético del padre de intención? ¿Podría en ese caso haber quedado reconocido como padre legal, accediendo como tal al Registro Civil sin necesidad de realizar ningún trámite intermedio como la adopción plena? En 
el caso mexicano parece ser que el Registro Civil no se negaba que el padre de intención, aunque biológico, estableciera una filiación, sino que se le obligaba a recurrir a un trámite de adopción plena para inscribir una filiación civil adoptiva, lo que sí ocurrió en Francia puesto que se negó el acceso al registro civil a los padres de intención (donde solo el varón había aportado su carga genética) impidiéndoseles judicialmente, establecer la filiación por posesión de estado o por adopción.

\section{Derecho a la identidad del menor, su acceso y tutela judicial efectiva a través de la instrumentalización de medidas cautelares}

En el caso que nos ocupa, mediante el trámite por separado del juicio principal y a través de un procedimiento incidental, el juez de distrito concedió la suspensión del acto reclamado consistente en la negativa de expedir el acta de nacimiento de la menor Rachel Mary Cyr, ordenando en consecuencia expedir una en forma cautelar, lo que no fue concretamente solicitado por los demandantes por lo que la orientación instrumental de esa medida se entiende en forma tácita como la suplencia de la deficiencia en la pretensión de los solicitantes, que juzgador integró en base una "interpretación conforme" (Miranda, 2014: 69-80). No obstante, ante ese panorama, el registro civil solicitó una aclaración manifestando una incertidumbre e imposibilidad jurídicamente para cumplir al no existir en la legislación civil de Tabasco la figura jurídica de acta de nacimiento provisional, asimismo, se especificara los plazos y términos en que deberán estar sujetos las autoridades ante quienes se presente el acta de nacimiento para que informen al registro civil sobre un hipotético trámite.

El juez de distrito en aras de salvaguardar el principio de interés superior del menor precisó que se había concedido la suspensión:

(...) para que el Titular de la Dirección General del Registro Civil del Estado de Tabasco, registre y/o inscriba a la citada menor de edad, debiendo expedirle de manera gratuita, su primera copia certificada del acta de registro de nacimiento. Asimismo... deberá hacer una anotación marginal o hacer constar dentro del acta que ésta es de carácter provisional, imponiendo la obligación a que las autoridades, instituciones o dependencias ante las que se presente ese documento, estarán forzadas a informar el trámite y motivo por el que se les exhibió, hasta en tanto se resuelve el fondo de este asunto; lo anterior, con la finalidad de salvaguardar derechos de un tercero y además que, de no hacerlo así, se dejaría en estado de indefensión a la infante, pues como se ha dicho el derecho a la identidad es un requisito sine que non para poder acceder a otros diversos, como son la salud, educación, entre otros.

Por otra parte, el juez de distrito abundó en que en ninguna parte se expresó que el acta debía ser provisional, sino que se tenía que registrar o inscribir inmediatamente a la menor. Esto, derivado del derecho humano de identidad y la obligatoriedad de ser registrado de manera inmediata a su nacimiento. Aunado a ello, se ordenaba hacer una anotación marginal, lo cual no implica que el acta sea provisional, ni mucho menos pugna con la legislación civil aplicable, tan es así que el Reglamento del Registro Civil del Estado de Tabasco, faculta a realizar distintos tipos de anotaciones al margen de las actas; como precisamente se ordenó hacer en tanto que el registro o inscripción de la menor, deriva de una medida suspensiva que tiene vigencia hasta en tanto cause ejecutoria el juicio de amparo, quedando subjudice su validez posterior a que se resuelva mediante sentencia definitiva.

Por último, en relación a la solicitud de especificar los plazos o términos en los que deberán sujetarse las autoridades, instituciones o dependencias, que informarán a la directora del Registro Civil del Estado de Tabasco, la existencia de un hipotético trámite. El juez aclaró que se indicó a la autoridad responsable que no se estableció término o plazo alguno, pues será está a la que, con base en a su legislación y atribuciones, corresponda imponerlos.

En esas condiciones, al estimar el juez que no se había dado cumplimiento a lo ordenado requirió para que en:

“...forma inmediata... dentro de las veinticuatro horas siguientes... sin que haya lugar a prórroga alguna, sirva dar cumplimiento a la medida cautelar; apercibida que, en caso de incumplimiento, se hará acreedora a una multa... Lo anterior, en el entendido que el desacato... podría dar 
origen... a que este órgano jurisdiccional ordene que se dé vista al Ministerio Público por la probable comisión... del delito de desobediencia....

El hecho de que el juez de distrito hubiera ordenado mediante la suspensión provisional y en forma cautelar el registro del nacimiento de la menor en forma inmediata, implica que el juez ponderó e hizo valer varias circunstancias, entre ellas:

En el Código Civil del Estado de Tabasco, el legislador hizo derivar presunciones de filiación derivada de un contrato de gestación por sustitución a favor de la "madre contratante" y que era ella quien debía comparecer al registro civil. En ese panorama el juez tuvo que ponderar que al ordenar el registro y establecer la filiación del padre de intención con la menor, protegía el ejercicio de la paternidad genética, como libre elección del proyecto de una vida familiar monoparental con la vida futura de un menor.

Con el reconocimiento de ese modelo familiar, se protegió la preservación de las relaciones familiares de facto entre el padre de intención y la recién nacida, realidad social que se estimó correspondía a la identidad de la menor y que era merecedora de inmediato amparo, sin la necesidad de judicializar el reconocimiento de la filiación paternal por medio de la adopción, al tenerse el mismo resultado. Dicho de otra forma, el juzgador tuvo que evaluar la no afectación del interés social, el orden público, "la apariencia del buen derecho" Manríquez, (2010), y, en su caso de la molestia tolerable de la sensibilidad social sobre la adopción de un modelo de virtud personal que se considere válido (Nino, 1989: p. 423), para entonces ponderar, con independencia de la verdad biológica, si de acuerdo con las circunstancias del caso, sería perjudicial para el menor desprenderlo del contexto social y familiar en el que nació y podría crecer, en el que posiblemente se formará un sentimiento de apego y de identidad que eventualmente no puede disolverse sin afectar los deseos e intereses del niño (SCJN, tesis 1a. LXXII/2017, 586). Por otro lado, la realidad social puede llegar a configurar la personalidad del menor, por lo que alterar su esquema familiar podría resultar en una afectación al derecho a la identidad Barudy, (2010). En ese sentido destaca el asunto Paradiso y Campanelli contra Italia, en el que los padres de intención, una pareja heterosexual que no había aportado su material genético, en el que la Corte Europea de Derechos Humanos estableció condena por no haber posibilitado vías para que los comitentes pudieran cuidar al niño que les fue separado y dado en adopción cuando se tuvo conocimiento de que había sido gestado por sustitución (Durán, 2014: 280-282).

\section{Derecho a la identidad y su materialización definitiva frente a la omisión de parientes}

En la sentencia definitiva se ordenó al Registro Civil realizar los trámites administrativos que se requieran para que se expidiera copia certificada del acta de nacimiento. La autoridad responsable solicitó la comparecencia personal del padre y la menor para que quedara en el acta de nacimiento: la impresión digital del menor, la firma del padre, los testigos y el Oficial del Registro Civil, los cuales no pueden omitirse en términos de dicho ordenamiento legal.

Ante la no presentación de los solicitantes; agotados todos los medios de notificación por estrados, vía electrónica y comunicación por medio del juez de distrito, incluso la manifestación expresa del representante legal de los demandantes de no presentarse y que el Registro Civil carece de medidas de apercibimiento legales para lograr la comparecencia referida. El juez de distrito consideró la imposibilidad para tener por cumplida la sentencia de amparo por causas imputables al padre de la menor, consecuentemente, conforme al procedimiento del juicio de amparo ordenó remitir el expediente al superior jerárquico, esto es, al Tribunal Colegiado en Materia Administrativa y de Trabajo, del Décimo Circuito, con residencia en Villahermosa, Tabasco a efecto de iniciar procedimiento de ejecución de la sentencia de amparo. Hasta el 15 de agosto de 2018, fecha del último acuerdo administrativo, no se ha emitido resolución en el incidente en mención.

El cumplimiento de la sentencia de amparo, implica su ejecución con base en el interés superior del menor y el orden público. La jurisprudencia nacional previa a la emisión de la sentencia había reconocido la existencia de principios rectores en materia de filiación que necesariamente informan la regulación de acciones como la de investigación y reconocimiento de paternidad. Entre estos 
principios se encuentran, la verdad biológica y la protección del interés del hijo (SCJN, Tesis: 1a. CCCXX/2014). El artículo 7, numeral 1, de la Convención sobre los Derechos del Niño, consagra el derecho a conocer a sus padres en la medida de lo posible; asimismo, la tendencia es que la filiación jurídica coincida con la filiación biológica (SCJN, Tesis: 1a. CCCXXI/2014). Lo que resulta relevante si se engarza con el criterio aislado de jurisprudencia recientemente publicado el pasado 17 de noviembre de 2017 que orienta en el sentido de que el permanecer en el desconocimiento de la verdad sobre su identidad de uno de los progenitores, es una afectación grave, ya que estaría incompleta su filiación, privándole de la oportunidad de la obtención de los satisfactores básicos derivados de la relación filial, aunado a que debe notarse que el hecho de que el niño tenga la certeza de quién es su progenitor, constituye un principio de orden público que es parte del núcleo esencial del derecho fundamental a la personalidad jurídica (STCMCTC, Tesis: III.2o.C.85 C).

\section{Vida privada, familiar y la publicidad de los actos del estado civil de las personas}

Como consecuencia de lo ordenado en la sentencia de fondo, realizar los trámites administrativos que se requieran para que se expida a los solicitantes copia certificada del acta de nacimiento, el juzgador precisó que en dicho documento no deberá contener anotación marginal, lo que es congruente con el respeto a la vida privada de la menor.

Por otra parte, el resolutor dedica un apartado en relación al respeto de la vida privada y familiar de los solicitantes, concluyendo:

(...) la transmisión del acuerdo de dieciséis de diciembre de dos mil dieciséis, dictado por la Directora General del Registro Civil en el Estado de Tabasco... en el que se declaró improcedente la solicitud de registro de la menor... por parte de la Delegación de la Secretaría de Relaciones Exteriores a la embajada de los Estados Unidos de Norte América, sí afecta el interés jurídico de los peticionarios de amparo.

(...) la referida comunicación puede estimarse una intromisión al ámbito propio y reservado de lo íntimo, que el quejoso deseaba mantener fuera del alcance de terceros o del conocimiento público, pues de otra manera él lo hubiese informado a su respectivo consulado.

En la misma la línea de argumentación judicial trascrita en el párrafo que precede, se debe tomar nota de que en forma cautelar se ordena expedir acta de nacimiento en favor de un menor, con la imposición de hacer anotación al margen en los siguientes términos:

(...) deberá hacer una anotación marginal o hacer constar dentro del acta que ésta es de carácter provisional, imponiendo la obligación a que las autoridades, instituciones o dependencias ante las que se presente ese documento, estarán forzadas a informar el trámite y motivo por el que se les exhibió, hasta en tanto se resuelve el fondo de este asunto; lo anterior, con la finalidad de salvaguardar derechos de un tercero y además que, de no hacerlo así, se dejaría en estado de indefensión a la infante, pues como se ha dicho el derecho a la identidad es un requisito sine que non para poder acceder a otros diversos, como son la salud, educación, entre otros.

Posteriormente a la expedición del acta de nacimiento en los anteriores términos, la representante legal de los quejosos solicitó se requiriera a la autoridad registral para que modificara la anotación marginal realizada. A lo que el juez accedió y ordenó:

(...) como lo solicita la promovente se requiere a la Dirección del Registro Civil del Estado de Tabasco, para que corrija la anotación marginal contenida en el acta de nacimiento... en virtud que en la aclaración de la suspensión definitiva se le indicó que el acta en comento no debía ser de carácter provisional, sino que tal registro deriva de una medida suspensional en términos del numeral citado y su vigencia iniciaba desde la expedición del acta de nacimiento hasta en tanto cause ejecutoria el juicio de amparo del que deriva la presente incidencia, quedando subjudice su validez posterior a que se resuelva mediante sentencia ejecutoriada.

Ha de resaltarse el acierto del resolutor para otorgar en forma cautelar el registro del 
menor. En este punto, la Corte Europea en el caso Mennesson y Labassee sostuvo que la falta de reconocimiento en la legislación francesa de filiación entre los menores con sus padres de intención afecta necesariamente a su vida familiar; consideró que el Consejo de Europa en su informe de 2009 sobre la revisión de leyes de bioética enfatizó que de hecho, la vida de las familias es más complicada en ausencia de la transcripción, debido a las formalidades que deben cumplirse en relación con ciertos acontecimientos en la vida. También se estimó, que debe tenerse en cuenta el hecho de que está en juego un aspecto esencial de la identidad de las personas cuando se trata de la relación jurídica entre padres e hijos (filiación). Por lo tanto, es necesario reducir el margen de apreciación otorgado al Estado y lograr un equilibrio justo entre el interés de la comunidad para garantizar que sus miembros cumplan con la elección democrática dentro de ella, incluido el interés superior de los niños, para disfrutar plenamente de los derechos al respeto de la vida privada y familiar.

En ese tenor, si el menor tiene derecho a ser registrado de forma inmediata al nacimiento como forma instrumental y garantía de acceso a su identidad y ello es una zona infranqueable, entonces surgen cuestionamientos como ilo que estaba subjudice era la existencia de su registro o la filiación respecto del padre de intención? Si el juzgador ponderó la anotación marginal como intromisión a la vida privada y familiar en aras de salvaguardar derechos de terceros ¿orientó esa ponderación con base al interés superior del menor?, considerando que ordenar la anotación marginal sobre el origen del registro del nacimiento de un menor y su validez subordinada, para dejarlo al arbitrio, sospecha o incomprensión de la persona ante quien se presente el inició de un trámite para el acceso al menor de servicios de educación, salud o el registro del nacimiento del menor o expedición de un pasaporte en otro país ¿lo deja en estado de indefensión? ¿Qué hace distinto comunicar la denegación de un acto de estado civil del menor a otro país o hacer público mediante una anotación marginal el origen y vigencia de una certificación registral de nacimiento? ¿Sería más grave la intromisión al ámbito de lo propio a la reserva de lo íntimo, ya que el alcance es mayor al ser público a donde quiera que se presente el documento?

\section{El interés del menor, el registro de la filiación de intención y el orden público del Estado de Tabasco y el diverso Nacional}

\subsection{Alusión a métodos expresos y no expresos en la ley para el registro de la filiación biológica.}

Aunque no se tiene la certeza de que todas las afirmaciones que expuso el Coordinador Jurídico de la Dirección General del Registro Civil del Estado de Tabasco en medios de comunicación, fueran alegadas y debidamente probadas en juicio, lo cierto es que el Gobierno centró la constitucionalidad del acto reclamado, la negativa, en la falta de facultades que la ley le otorgaba para registrar al menor, puesto que el asiento registral debía hacerse conforme a la reforma vigente al momento del nacimiento de la menor, mediante un juicio previo de adopción plena. Cabe destacar que el juez de distrito hizo pronunciamiento en relación a la intención (teleología) del legislador, la relación del menor con la gestante, el interés del menor y del padre de intención.

Lo singular es que el juzgador no solo define que en el presente caso la ley aplicable era la anterior a la reforma; además advierte que la ley anterior vigente a la firma del contrato colocaba aparentemente a la menor en la misma circunstancia de tener que agotar un procedimiento de adopción para asentar el registro de su nacimiento, por lo que en un ejercicio de "interpretación conforme" analiza la teleología de la norma y concluye que existe un error en la redacción de la ley y por tanto, no procedía que la menor acudiera al trámite de la adopción en tanto que la filiación podía establecerse mediante el reconocimiento voluntario del padre de intención en la partida de nacimiento ante el Registro Civil. Finalmente, el juzgador hace referencia tácita a un principio de igualdad del menor independientemente de las circunstancias del nacimiento y a una atenuación o "efecto mitigado del orden público" al declarar que en el ordenamiento civil no se encontraba inmerso dispositivo alguno que contenga la prohibición de realizar el asentamiento de un menor a quien demuestre ser su padre biológico. Lo que cobra relevancia, puesto que en el mismo tenor, en el caso Mennesson y Labassee contra Francia, los solicitantes invitan a la Corte a seguir el mismo razonamiento que en los juicios Pla y Puncernau contra Andorra y, Wagner contra Luxemburgo, en 
relación al principio de la igualdad de las filiaciones sobre las circunstancias del nacimiento (adopción internacional), Mazurek contra Francia en la que se consideró que "no se puede culpar al niño adúltero por hechos que no le son imputables".

El razonamiento para estimar la finalidad de la norma y el error de redacción en la ley, estribó en que el Código Civil de Tabasco distingue entre madre subrogada y madre sustituta, la diferencia es que la primera aporta componente genético y el gestante, la segunda solo el gestante. En esas condiciones la ley vigente a la firma del contrato de gestación por sustitución disponía que para que la adopción plena tuviera lugar se requería entre otros supuestos, que el menor sea producto de un embarazo logrado como consecuencia del empleo de inseminación artificial o fertilización in vitro con la participación de una madre sustituta que haya convenido con los presuntos padres darlo en adopción; concluyendo que la palabra "sustituta" no puede tenerse más que como un error legislativo, ya que del ordenamiento sustantivo civil se desprendía que la adopción plena solo es necesaria para los casos de madre subrogada, es decir aquella que aporta material genético $y$, por tanto, es la madre biológica del menor, ya que la entrega del recién nacido a la madre contratante implica renuncia de derechos y la destrucción legal del vínculo natural que existe entre la madre que aporta material genético y el infante.

Con reserva ha de cuestionarse, si la resolución judicial fue necesariamente omisa ante la ausencia de la actividad contenciosa de las autoridades llamadas a juicio o, debidamente contenida con relación a un exceso de actividad judicial Osuna (2015); Gutiérrez (2016) y respetuosa de las relaciones familiares de facto e intimidad para que no sean conocidos por terceros ciertos aspectos de su vida privada, ello al omitir las presunciones del parto y, no orientar el interés superior del niño para establecer la integración total de la verdad biológica para conocer, en la medida de lo posible, la correspondencia gamética del óvulo fecundado o la desvinculación de la maternidad biológica de la gestante.

Sobre esta cuestión, la parentalidad genética ordinariamente se integra al menos por dos individuos (gameto masculino y femenino) o tres, cuando la tercera persona (mujer) aporta el ADN mitocondrial. En la especie, no fue controvertida por las autoridades llamadas a juicio el resultado de la prueba de exclusión de paternidad realizada por un laboratorio privado. Tampoco se instó para descartar que efectivamente la gestante no hubiera aportado su carga genética con la intención de que el menor, en la medida de lo posible, conociera sus orígenes genéticos, en atención a que jurisprudencia nacional ha integrado que la identidad es un derecho del hijo y no una facultad de los padres para hacerlo posible y; que permanecer en el desconocimiento de la verdad sobre su identidad de uno de los progenitores, es una afectación grave, ya que estaría incompleta su filiación, privándole de la oportunidad de la obtención de los satisfactores básicos derivados de la relación filial, aunado a que debe notarse que el hecho de que el niño tenga la certeza de quién es su progenitor, constituye un principio de orden público que es parte del núcleo esencial del derecho fundamental a la personalidad jurídica, que incluso traer instrumentalmente beneficios en la salud (prevención y tratamiento de enfermedades) o sucesorios (en relación al padre de intención que no aporta su carga genética).

En el mismo sentido se ha estimado que recibir información sobre el origen biológico, trae en beneficio del menor en su derecho a la salud, en su vertiente de prevención y tratamiento (Durán, 2014: 280-282), incluso sucesorios como lo señala la sentencia Mennesson y Labassee.

\subsection{Orden público, carga ideológica de la maternidad y finalidad del legislador}

Finalmente, el juzgador hace referencia a la ponderación que hace entre el interés del menor y el orden público en relación a cierto grado de maternidad en la gestación, la legitimación del legislador para impedir el tráfico de infantes y la manipulación genética en la siguiente conclusión:

(...) Ahora, el suscrito juzgador no pasa por alto que si bien es cierto durante la gestación se forman lazos sentimentales entre el menor con la madre gestante, así como el hecho de que la reforma al Código Civil tiene como finalidad la de impedir que se comercialice con la vida humana, ya que no puede ser objeto de transacción y garantizar el compromiso ético y social de poner límites sobre la manipulación científica de la naturaleza, pues 
su propósito debe ser sólo el de facilitar la vida del ser humano como núcleo esencial del tejido social; no menos cierto es que no por eso puede permitirse la aplicación de las disposiciones reformadas; pues en toda caso, la legislación antes de la modificación prevé procedimientos para la protección y solución jurídica de cualquier conflicto o protección.

Que en el fallo se aluda a la atribución de cierto grado de maternidad a la gestante, evidencia la carga ideológica que sopesó el juzgador en relación al orden público con el interés superior del menor. La doctrina preponderante se ha encaminado en denominar al acto de reproducción en cuestión como gestación por sustitución, empero, ha de decirse, que ha existido una cuestión ideológica al respecto de la correcta terminología. Por una parte, se sostiene que frente al acto reproductivo interpelado existe la disociación de la maternidad, considerando que no es madre ni la gestante ni quien dona el óvulo o el ADN mitocondrial sino con exclusividad la madre de intención quien es la que tiene la voluntad procreativa Lamm (2013). Por otro lado, se considera que la maternidad se extiende y se tienen varios grados de maternidad con relación al papel que se desempeña, incluso se habla de una "maternidad masculina" Suarez (2011) que considera que la maternidad como experiencia humana no es exclusivamente del sexo femenino.

En la línea de la extensión de la maternidad, puede citarse el caso "Baby M", en el que la Suprema Corte de New Jersey declaró nulo el contrato de gestación por sustitución por ilícito, entre otras, no preveía la cláusula del asesoramiento y; estaba basado en el pago de dinero. El tribunal Ad Quem, hace una reflexión en relación al consentimiento nulo e irrelevante de Mary Beth Whitehead, viciado por las condiciones económicas y culturales, concluyendo desde entonces con una frase que Michael Sandel popularizara: "hay cosas que el dinero no puede comprar" en atención a que una conducta "voluntaria" comprada con dinero no significa que sea buena ni que estuviera más allá del orden público. Finalmente, el tribunal de apelación, confirma la concesión de la custodia al padre genético, revoca la declaración de la perdida de los derechos maternos de la madre genética (gestante) dictada por el $A$ quo, requiriendo al inferior a efecto de que determinara las modalidades de la convivencia entre la menor y esta última (Richards, 2015).El caso en mención constituye el primer paso de reflexión ética y jurídica, no solo en el sistema jurídico de los Estados Unidos de Norteamérica, sino en el mundo entero, puesto que allí se pone de manifiesto la necesidad de replantear y cuestionar las normas vigentes en materia de filiación derivada de contratos de gestación por sustitución.

Lo anterior redunda en afirmar en forma eclética tanto la disociación como la extensión de la parentalidad en lo que se ha denominado por Maurice Godelier como la "metaformosis del parentesco" en donde la "sexualidad reproducción" tiene un sentido social y las relaciones que se establecen entre miembros de los mismos grupos de filiación en sí mismas no significan nada, pues son otros los elementos que las determinan y las hacen significantes (Vinatea, 2012: 225-247). Así, en la opinión de Buxo Rey (2004), es conveniente aceptar de manera flexible modelos de parejas de relación, procreación y adopción, al igual que la monoparentalidad es adecuada para hombres y mujeres, donde no son relevantes la edad, identidad sexual, número de miembros, vocación, altruismo, sino la voluntad y ternura de ser padre o madre. Al final, las denominaciones son lo mismo y no lo son, son las voces de distintos interlocutores definiendo un mismo objeto (Lazcoz, 2016).

\section{CONCLUSIONES}

El acta de nacimiento o certificación registral que se expida basada en la sentencia del juicio de amparo (sosteniéndose la constitucionalidad del acto por la autoridad versus la pretensión de los solicitantes) en relación al registro inmediato de un menor con inmediatez a su nacimiento sin agotar instancias judiciales previas, no será reflejo secundario de una diversa resolución judicial del fuero común (juzgado familiar) como mera formalización de un procedimiento de adopción plena, donde no existe una contienda entre partes.

En forma expresa en la resolución judicial, mediante una interpretación conforme, se delimitó el perímetro material del interés superior del menor en comunidad con una paternidad de intención derivada de un contrato de gestación por sustitución y el orden público, considerándose que es violatorio del derecho a la identidad del menor impedir la realización del asentamiento del registro del nacimiento de un menor por quien demuestre ser su padre biológico mediante la obligación de instar un juicio previo no contencioso de adopción plena; 
no obstante que durante la gestación se forman lazos sentimentales entre el menor con la madre gestante, así como el hecho de que el legislador tenga como finalidad la de impedir que se comercialice con la vida humana y la manipulación científica de la naturaleza.

En forma tácita, la resolución judicial valora que formal y materialmente no existió: (i). Alguna vulneración del interés del menor o de la mujer gestante; (ii). Vicio en el contrato como la obtención del consentimiento incurriendo en error, dolo o violencia o incapacidad natural o; (iii) Existencia de noticia en relación a que se hubiera ejercitado facultad de revocación del consentimiento sin haberse reconocido. Lo anterior, considerando que el juez tuvo a la vista el contrato denominado "de gestación materna sustituta" y que fueron llamadas a juicio no solo las autoridades señaladas como responsables, además el Ministerio Público Federal, el Sistema para el Desarrollo Integral de la Familia, la Procuraduría Estatal de Protección de la Familia y Derechos de las Niñas, Niños y Adolescentes de Tabasco y la Comisión Estatal de los Derechos Humanos de Tabasco, cuya misión se enfoca en la persecución de los delitos y la protección de derechos humanos.

En ese contexto, la decisión del juez de distrito constituye la extensión de la delimitación perimetral del derecho a la identidad en el sentido de que va más allá del discurso Europeo e Intermericano de derechos humanos que han definido ilegítima la intervención a la vida privada del menor impedir el establecimiento de su filiación correspondiente que ha definido como mínimo el acceso al registro de la realidad biológica y en su caso la realidad social de un menor mediante el reconocimiento, adopción o posesión de estado de hijo. La decisión del tribunal mexicano implica en forma expresa la extensión de esa frontera, siendo más garantista y; en forma implícita orientar la política pública a un nuevo mínimo exigible. En ese sentido el Estado de Tabasco deberá considerar al menos administrativamente, con independencia de las circunstancias de nacimiento: primero, hacer inscribir la filiación de un menor por quien acredite la parentalidad biológica lisa y llanamente o por reconocimiento y; segundo, sin imponer un previo juicio de adopción plena, facilitar la igualdad registral entre hombres y mujeres que acrediten la parentela genética con independencia de modelos familiares. Patente está, que en el caso concreto existió un control de Derecho por parte de órgano del poder judicial de la federación como titular del control concentrado de constitucionalidad, sobre un acto del estado civil, cuyo ámbito de competencia originalmente corresponde al fuero común (juzgados familiares de las entidades federativas), en la que frente a una eventualidad concreta se interpretó el campo de aplicación del principio del interés superior del menor. 


\section{BIBLIOGRAFÍA}

- Arudy, J. (2010). "Los buenos tratos y la resilencia infantil en la prevención de los trastornos del comportamiento". Fundación Internacional $0^{\prime}$ Belén. Recuperado de https://www.obelen.es/upload/383D.pdf.

- Bundesgerichtshof Beschluss (Tribunal Federal Alemán). (2014). XII ZB 463/13, Recuperado de http:// juris.bundesgerichtshof.de/cgi-bin/ rechtsprechung/document.py?Gericht=bgh \&Art $=$ pm \&Datum $=2014 \&$ Sort $=3 \& a n z=193$ \&pos $=1 \& n r=69759 \&$ linked=bes $\&$ Blank $=1 \&$ file=dokument.pdf.

- Buxó, M. (2004). "Familia en plural". Reinventar la Familia. VI Jornada del Centre Alberto Campo. Barcelona: Edición CRIPS.

- Comisión Estatal de Derechos Humanos de Chihuahua CEDHC. (2017). Gaceta Edición Enero-Abril 2017. Recuperado de: http:// www.cedhchihuahua.org.mx/portal/ Gaceta/2017/enero-abril-web.pdf.

- Consejo de la Judicatura Federal. (2017). Lista de acuerdos publicada el 23 de febrero de 2017 en los estrados del Juzgado Segundo de Distrito, Villahermosa, Tabasco, de Poder Judicial de la Federación. Recuperado de http://sise.cjf.gob.mx/ SiseInternet/Actuaria/VerAcuerdo.aspx?lis taAcOrd=39\&listaCatOrg=517\&listaNeun= 20287862\&listaAsuId=1\&listaExped $=53 / 2$ $017 \&$ listaFAuto $=21 / 02 / 2017$ \&listaFPublic acion $=23 / 02 / 2017$.

- Corte Europea de Derechos Humanos. (1992). Niemietz Vs. Alemania. Sentencia de 16 de diciembre de 1992, (No. 13710/88), Recuperado de http://hudoc.echr.coe.int/ fre? $\mathrm{i}=001-62344$.

- --.--. (2002). Pretty contra Reino Unido. Sentencia de 29 de abril de 2002, (No. 2346/02). Recuperado de http://hudoc. echr.coe.int/fre?i=001-65003.

- ------. (2003). Peck contra Reino Unido. Sentencia de 28 de abril de 2003, (No. 44647/98). Recuperado de http://hudoc. echr.coe.int/fre?i=001-65455

- ------. (2011). R.R. contra Polonia. Sentencia del 26 de mayo de 2011, (No. 27617/04). Recuperado de http://hudoc. echr.coe.int/fre?i=001-104911.

- -------. (2012). Dudgeon contra Reino Unido. Sentencia de .24 de febrero de 1983, (No. 7525/76). Recuperado de http://hudoc.echr.coe.int/fre?i=001-62030.

- -------- (1985). X y $Y$ contra Países Bajos. Sentencia de 26 de marzo de 1985, (No. 8978/80). Recuperado de http://hudoc. echr.coe.int/fre?i=001-62162.

- Corte Interamericana de Derechos Humanos. (2002). Condición Jurídica y Derechos Humanos del Niño. Opinión Consultiva OC-17/02 del 28 de agosto de 2002, Serie A No. 17. Recuperado de http:// www.corteidh.or.cr/docs/opiniones/seriea_17_esp.pdf.

- -------. (2007). Chaparro Álvarez y Lapo Íñiguez. Vs. Ecuador. Sentencia de 21 de noviembre de 2007, Serie C No. 170. Recuperado de http://www.corteidh.or.cr/ docs/casos/articulos/seriec 170 esp.pdf.

- -----. (2010). Rosendo Cantú y otra Vs. México. Excepción Preliminar, Fondo, Reparaciones y Costas. Sentencia de 31 de agosto de 2010, Serie C No. 216. Recuperado de http://www.corteidh.or.cr/ docs/casos/articulos/seriec 216 esp.pdf.

- ------. (2011). Gelman Vs Uruguay. Sentencia de 24 de febrero de 2011, Serie C No. 221, Recuperado de http://www. corteidh.or.cr/docs/casos/articulos/seriec 221 esp1.pdf.

- --------. (2012). Atala Riffo y Niñas Vs. Chile. Fondo, Reparaciones y Costas. Sentencia de 24 de febrero de 2012. Recuperado de: http://corteidh.or.cr/docs/casos/articulos/seriec 239 esp.pdf.

- Durán, A. (2012). El acceso al Registro Civil de certificaciones registrales extranjeras a la luz de la Ley 20/2011: relevancia para los 
casos de filiación habida a través de gestación por sustitución. Anuario español de Derecho internacional privado, 12, 265 - 308.

- -------. (2014). Sentencias del Tribunal Europeo de Derechos Humanos, caso Mennesson c. France (n. $\stackrel{0}{65192 / 11)}$ y caso Labassee c. France (n.. 65941/11). Interés superior del menor y gestación por sustitución. Revista Europea e Iberoamericana de Pensamiento y Análisis de Derecho, Ciencia Política y Criminología, 2 (2), 280 - 282.

- Durángo, A. (2016). Una encrucijada judicial y una reforma legal por hacer: problemas jurídicos de la gestación por sustitución en España. A propósito del auto del Tribunal Supremo de 2 de febrero de 2015. Bitácora Millennium DIPr, 1 (2), 1 - 16.

- Farnós, E. (2017). Paradiso y Campanelli c. Italia (II): los casos difíciles crean mal derecho. Revista de Bioética y Derecho, (40), 231-242. Recuperado de: http://www. redalyc.org/html/783/78351101017/.

- Flores, J. (2014). Gestación por sustitución: más cerca de un estatuto jurídico europeo. Revista de Derecho Privado, (27), 71-89. ISSN 0123-4366.

- Gutiérrez, A. (2016). El amparo estructural de los derechos (tesis doctoral). Universidad Autónoma de Madrid, Facultad de Derecho. Recuperado de: https://repositorio.uam. es/bitstream/handle/10486/676669/ gutierrez beltran andres mauricio. pdf? sequence $=1$.

- Hernández, P. (2017). Tabasco, el viacrucis de la maternidad subrogada. Recuperado de: http://www.elfinanciero.com.mx/ nacional/tabasco-el-viacrucis-de-lamaternidad-subrogada.html.

- Lamm, E. (2013). Gestación por sustitución: ni maternidad subrogada ni alquiler de vientres. España: Publicacions i Edicions de la Universitar de Barcelona.

- Lamm, E., y Rubaja, N. (2016). Parámetros jurisprudenciales en los casos de gestación por sustitución internacional.
Los lineamientos del Tribunal Europeo de Derechos Humanos y sus repercusiones en el contexto global. Revista de Bioética y Derecho (37).

- Lazcoz, G. (2016). Construyendo un diálogo: gestación por sustitución", Promoción del Master en Derecho Sanitario. Madrid: Universidad de San Pablo.

- Ledeser. (2017). Litigio Estratégico en Derechos Sexuales y Reproductivos. Recuperado de https://ledeser.org/ quienes-somos

- Manríquez, C. (2010). La apariencia del buen derecho en el juicio de amparo mexicano. Revista Del Instituto De La Judicatura Federal, (10), 153 - 178. Recuperado de https://www.ijf.cjf.gob.mx/ publicaciones/revista/10/10_7.pdf.

- Miranda, A., y Rodríguez, P. (2014). El principio de interpretación conforme en el derecho constitucional mexicano. Revista Opinión Jurídica, 13, (26), 69-80. Recuperado de http://www.scielo.org.co/ pdf/ojum/v13n26/v13n26a05.pdf.

- Nino, C. (1989). Ética y Derechos Humanos. Un ensayo de fundamentación. Buenos Aires: Astrea.

- Osuna, N. (2015). Las sentencias estructurales. Tres ejemplos de Colombia, de Justicia constitucional y derechos fundamentales. México: Instituto de Investigaciones Jurídicas de la UNAM. Recuperado de: https://archivos.juridicas. unam.mx/www/bjv/libros/10/4504/7.pdf

- Suprema Corte de Justicia de la Nación (SCJN). (2014). Filiación. forma en que operan los principios rectores en la materia aplicados a casos concretos. Gaceta del Semanario Judicial de la Federación, Libro 10, septiembre de 2014, Tomo I, 578.

- ------- (2014a). Filiación. alcances y límites del principio de verdad biológica. Gaceta del Semanario Judicial de la Federación, Libro 10, septiembre de 2014, Tomo I; Materia(s): Constitucional, Civil, 577. 
- -----..-(2017). Principio delmantenimiento del menor en la familia biológica. evaluación de la consolidación de una realidad social distinta a la biológica. Gaceta del Semanario Judicial de la Federación, Libro 43, junio de 2017, Tomo I, 586.

- Reinoso, F. (2009). Foro de Conveniencia, Derecho de Conveniencia y Nulidad. Revista de Derecho UNED, (4). Recuperado de: http://revistas.uned.es/index.php/ RDUNED/article/view/10974/10502.

- Reyes, J. (2017). Corte atrae caso de vientres rentados. Excelsior. Recuperado de: http://www.excelsior.com.mx/ nacional/2017/03/05/1150193.

- Richards, E. (2015). "First Surrogacy Case In re Baby M, 537 A.2d 1227, 109 N.J. 396 (N.J. 02/03/1988)". Louisiana: LSU Law Center. Recuperado de http://biotech.law. lsu.edu/cases/cloning/baby m.htm

- Segundo Tribunal Colegiado en materia Civil del Tercer Circuito (STCMCTC). (2017). Prueba pericial en genética. si el infante se opone a su admisión, aduciendo transgresión a sus derechos a la dignidad humana y a la intimidad, y ello origina una colisión entre derechos que pretenden tutelar el interés superior del niño, debe priorizarse su derecho a conocer su identidad biológica sobre éstos. Semanario Judicial de la Federación, viernes 17 de noviembre de 2017.

- Silva, P. (2001). Baby M y el Contrato de Maternidad Subrogada, Sustituta o Suplente. Boletín del Ministerio de Justicia, España, (1503), 38-76. Recuperado de http://www.mjusticia.gob.es/cs/Satelli te/1292344065158?blobheader=applic ation\%2Fpdf\&blobheadername1=Conte nt-Disposition\&blobheadername $2=$ Estu dioDoctrinal\&blobheadervalue1=attachment\%3B+filename\%3D1988 1503.pdf\&b lobheadervalue $2=1288777293577$.

- Suarez, J. (2011). La maternidad masculina y otros ensayos sobre la igualdad entre mujeres y hombres desde otro punto de vista. España: Dykinson.

- Televisa. (2017). Tabasco niega acta de nacimiento a 11 bebés gestados en vientres de alquiler. Recuperado de: http:// noticieros.televisa.com/ultimas-noticias/ estados/2017-02-21/tabasco-niega-actanacimiento-11-bebes-gestados-vientresalquiler/.

- Vinatea, E. (2012). Maurice Godelier. Elogio y defensa de la antropología. Papers Revista de Sociología, 97, (1), 225-247. 